\title{
Epigenetic alteration at the DLKI-GTL2 imprinted domain in human neoplasia: analysis of neuroblastoma, phaeochromocytoma and Wilms' tumour
}

\section{Astuti', F Latif 1,2, K Wagner', D Gentle', ${ }^{1,2}$ WN Cooper', D Catchpoole ${ }^{3}$, R Grundy ${ }^{4}$, AC Ferguson-Smith $^{5}$ and ER Maher ${ }^{*, 1,2}$}

'Department of Paediatrics and Child Health, Section of Medical and Molecular Genetics, University of Birmingham, The Medical School, Edgbaston, Birmingham B 5 2T, UK; ${ }^{2}$ Cancer Research UK Renal Molecular Oncology Research Group, University of Birmingham, The Medical School, Edgbaston, Birmingham B 5 2TT, UK; ${ }^{3}$ TBA; ${ }^{4}$ Department of Paediatric Oncology Birmingham Children's Hospital and Department of Paediatrics and Child Health, University of Birmingham, B 5 2TT; ${ }^{5}$ Department of Anatomy, University of Cambridge, Downing Street, Cambridge CB2 3DY, UK

Epigenetic alterations in the IIp 5.5 imprinted gene cluster are frequent in human cancers and are associated with disordered imprinting of insulin-like growth factor (IGF)2 and HI9. Recently, an imprinted gene cluster at I4q32 has been defined and includes two closely linked but reciprocally imprinted genes, DLKI and GTL2, that have similarities to IGF2 and HI9, respectively. Both GTL2 and HI 9 are maternally expressed RNAs with no protein product and display paternal allele promoter region methylation, and DLKI and IGF2 are both paternally expressed. To determine whether methylation alterations within the 14q32 imprinted domain occur in human tumorigenesis, we investigated the status of the GTL2 promoter differentially methylated region (DMR) in 20 neuroblastoma tumours, 20 phaeochromocytomas and, 40 Wilms' tumours. Hypermethylation of the GTL2 promoter DMR was detected in $25 \%$ of neuroblastomas, $10 \%$ of phaeochromocytoma and $2.5 \%$ of Wilms' tumours. Tumours with GTL2 promoter DMR hypermethylation also demonstrated hypermethylation at an upstream intergenic DMR thought to represent a germline imprinting control element. Analysis of neuroblastoma cell lines revealed that GTL2 DMR hypermethylation was associated with transcriptional repression of GTL2. These epigenetic findings are similar to those reported in Wilms' tumours in which HI 9 repression and DMR hypermethylation is associated with loss of imprinting (LOI, biallelic expression) of IGF2. However, a neuroblastoma cell line with hypermethylation of the GTL2 promoter and intergenic DMR did not show LOI of DLKI and although treatment with a demethylating agent restored GTL2 expression and reduced DLKI expression. As described for IGF2/HI9, epigenetic changes at DLKI/GTL2 occur in human cancers. However, these changes are not associated with DLKI LOI highlighting differences in the imprinting control mechanisms operating in the IGF2-HI 9 and DLKI-GTL2 domains. GTL2 promoter and intergenic DMR hypermethylation is associated with the loss of GTL2 expression and this may contribute to tumorigenesis in a subset of human cancers.

British Journal of Cancer (2005) 92, I574- 1580. doi:I0.1038/sj.bjc.6602478 www.bjcancer.com

Published online 29 March 2005

(c) 2005 Cancer Research UK

Keywords: imprinting; DLKI; GTL2; methylation

Genomic imprinting is a process whereby imprinted genes demonstrate parent-of-origin differences in allelic expression. Although only a minority of genes are imprinted, many of those identified to date have a role in the regulation of cell growth and differentiation and aberrant imprinting frequently leads to abnormal pre- and/or postnatal growth (Reik and Walter, 2001). Furthermore, disordered imprinting has been implicated in the pathogenesis of paediatric and adult cancers. Imprinted genes frequently occur in clusters. In particular, the imprinted gene

*Correspondence: Professor ER Maher, Department of Paediatrics and Child Health, Section of Medical and Molecular Genetics, University of Birmingham, The Medical School, Edgbaston, Birmingham BI5 2TT, UK; E-mail: E.R.Maher@bham.ac.uk

Received 17 September 2004; revised 16 December 2004; accepted I February 2005; published online 29 March 2005 cluster at $11 \mathrm{p} 15.5$, which contains the paternally expressed insulinlike growth factor (IGF) 2 and the maternally expressed CDKN1C and $\mathrm{H} 19$ genes has been implicated in disorders of growth and in neoplasia (Maher and Reik, 2000; Feinberg et al, 2002). For example, germline-inactivating mutations in CDKN1C and epigenetic alterations leading to the loss of imprinting (LOI) (biallelic expression) of IGF2 and silencing of CDKN1C or H19 cause Beckwith-Wiedemann syndrome, a congenital overgrowth disorder associated with susceptibility to embryonal tumours (Maher and Reik, 2000; Weksberg et al, 2003). In addition, epigenetic alterations at IGF2 and $H 19$ have been implicated in the pathogenesis of sporadic childhood (e.g. Wilms' tumour) and adult (e.g. colorectal) cancers (Cui et al, 2001; Nakagawa et al, 2001). IGF2 and $H 19$ are closely linked and reciprocally imprinted, and epigenetic alterations in human cancers at an intergenic differentially methylated region (DMR) are associated with LOI of IGF2 and silencing at $H 19$. 
In the past decade, the imprinted gene clusters at $11 \mathrm{p} 15.5$ and 15q13 (Prader-Willi and Angelman syndrome region) have been the subject of intense investigation. Recently, an imprinted gene cluster at $14 \mathrm{q} 32$ (distal mouse chromosome 12) was identified. The first imprinted 14q32 gene identified was GTL2/Gtl2, which, like $H 19$, is a maternally expressed RNA with no apparent open reading frame (Miyoshi et al, 2000). Subsequently, a paternally expressed gene, $D L K 1 / D l k 1$, which encodes an EGF-like membrane protein similar to the Drosophila Delta gene was identified upstream of GTL/Gtl2 (Kobayashi et al, 2000; Schmidt et al, 2000; Takada et al, 2000; Wylie et al, 2000). There are a number of similarities between the IGF2/H19 and the DLK1/GTL2 domains. In both cases, two closely linked genes are similarly organised, reciprocally imprinted and developmentally regulated; H19 and GTL2 do not encode known proteins, and paternally methylated DMRs associated with both genes have been implicated in the regulation of their imprinting (Paulsen et al, 2001; Takada et al, 2002).

In sheep, a single-nucleotide (nt) substitution is associated with altered postnatal expression of GTL2 and DLK1, although their imprinting is not perturbed. This mutation results in the Callipyge muscle hypertrophy phenotype (Charlier et al, 2001; Freking et al, 2002; Georges et al, 2003). In human mutations or epigenetic alterations of DLK1 and GTL2 have not been described, although distinct phenotypes associated with maternal and paternal disomy for chromosome 14 are reported (Georgiades et al, 2000; Eggermann et al, 2001; Kurosawa et al, 2002). SAGE analysis demonstrated high expression of DLK1 in a subset of neuroblastoma (van Limpt et al, 2000), but a follow-up study did not find any genetic alterations (e.g. mutation, duplication or rearrangement) or LOI in neuroblastomas with DLK1 overexpression (van Limpt et al, 2003). In addition, downregulation of GTL2 has been reported in pituitary adenomas with ectopic expression of GTL2 inhibiting tumour growth in vitro, suggesting a tumour suppressor function for that gene (Zhang et al, 2003).

We have investigated neuroblastoma and other tumours to determine whether epigenetic alterations within the DLK1-GTL2 imprinted domain are a feature of human neoplasia. We investigated neuroblastoma and phaeochromocytoma as DLK1 is highly expressed in the adrenal medulla. Neuroblastoma may also demonstrate $14 \mathrm{q}$ allele loss and Wilms' tumour was of interest as epigenetic alterations at the IGF2/H19 locus are common in this tumour.

\section{MATERIALS AND METHODS}

\section{Multiplex methylation polymerase chain reaction (mPCR) assay}

Methylation-specific PCR with oligonucleotide primers specific for the methylated and unmethylated copies of the GTL2 promoter on chromosome $14 \mathrm{q} 32$ were performed using previously published primers (Murphy et al, 2003): MSM-UF (5'-GAG GAT GGT TAG TTA TTG GGG T-3'; nt position 65912 (GenBank accession no. AL117190)); MSM-UR (5'-CCA CCA TAA CCA ACA CCC TAT AAT CAC A-3'; nt 65931-66004); MSM-MF (5'-GTT AGT AAT CGG GTT TGT CGG C-3'; nt 64450-64471) and MSM-MR ( $5^{\prime}$-AAT CAT AAC TCC GAA CAC CCG CG-3'; nt 64587-64609). The multiplex mPCR conditions used were initial denaturation at $95^{\circ} \mathrm{C}$ for $3 \mathrm{~min}$; five cycles of $95^{\circ} \mathrm{C}$ for $30 \mathrm{~s}, 70^{\circ} \mathrm{C}$ for $30 \mathrm{~s}, 72^{\circ} \mathrm{C}$ for $30 \mathrm{~s}$; five cycles of $95^{\circ} \mathrm{C}$ for $30 \mathrm{~s}, 65^{\circ} \mathrm{C}$ for $30 \mathrm{~s}, 72^{\circ} \mathrm{C}$ for $30 \mathrm{~s}$; followed by 30 cycles of $95^{\circ} \mathrm{C}$ for $30 \mathrm{~s}, 60^{\circ} \mathrm{C}$ for $30 \mathrm{~s}, 72^{\circ} \mathrm{C}$ for $30 \mathrm{~s}$ and a final extension of $72^{\circ} \mathrm{C}$ for $5 \mathrm{~min}$. PCR amplification were performed using $0.05 \mathrm{U}^{-1}$ Taq polymerase in $\left(\mathrm{NH}_{4}\right)_{2} \mathrm{SO}_{4}$ buffer with $3.0 \mathrm{~mm}$ $\mathrm{MgCl}_{2}$ (MBI Fermentas, St Leon-Rot, Germany). PCR products (160 bp for methylated allele and $120 \mathrm{bp}$ for unmethylated) were separated on a $3 \%$ agarose gel, stained with ethidium bromide and visualised under UV illumination.
Analysis of DNA methylation using bisulphite sequencing

Genomic DNA was treated with sodium bisulphite using previously published method (Herman et al, 1996). DNA $(0.5-1 \mu \mathrm{g})$ was denatured at $37^{\circ} \mathrm{C}$ for $10 \mathrm{~min}$ in $0.3 \mathrm{M} \mathrm{NaOH}$ followed by sulphonation of unmethylated cytosines by incubation in $3.12 \mathrm{M}$ sodium bisulphite containing $1 \mathrm{~m}$ hydroquinone $(\mathrm{pH} 5)$ at $95^{\circ} \mathrm{C}$ for $30 \mathrm{~s}$ and $50^{\circ} \mathrm{C}$ for $15 \mathrm{~min}$ for 20 cycles. The resulting sulphonated DNA was purified using the Wizard DNA clean-up system (Promega, Southampton, UK) according to the manufacturer's instructions and DNA was eluted with $50 \mu \mathrm{l}$ of distilled water. Following elution, DNA was desulphonated in $0.3 \mathrm{M} \mathrm{NaOH}$ for $5 \mathrm{~min}$ at room temperature, ethanol precipitated and resuspended in $50 \mu \mathrm{l}$ distilled water.

\section{Methylation status of GTL2 and DLK1 DMRs}

Following multiplex PCR methylation screening (see above), the methylation status of three areas of the CpG-rich region upstream of GTL2 were analysed in detail (G1, position 65897-66197; G2, position 66541-66920; G3, position 67541-67910; GeneBank accession no. AL117190; relative to GTL2 transcription start site, $\mathrm{G} 1=-363 \mathrm{bp} \rightarrow-161 \mathrm{bp}$ upstream; $\mathrm{G} 2=+293 \mathrm{bp} \rightarrow+673 \mathrm{bp}$ downstream; G3 $=+1213 \mathrm{bp} \rightarrow+1583$ bp downstream GTL2 transcription start site; GeneBank accession no. AY314975) and a region upstream DLK1 promoter (D1, position 140551-140810; GeneBank accession no. AL132711) and two downstream regions (D2, position 141271-141420; D3, position 141571-141894; GeneBank accession no. AL132711). Except for D1 and D2 regions, bisulphite-modified DNA was amplified using two rounds of nested PCR $\left(95^{\circ} \mathrm{C}\right.$ for $15 \mathrm{~min}$ followed by 35 cycles of $95^{\circ} \mathrm{C}$ for $30 \mathrm{~s}$, $55-58^{\circ} \mathrm{C}$ for $30 \mathrm{~s}, 72^{\circ} \mathrm{C}$ for $30 \mathrm{~s}$ and a final extension of $72^{\circ} \mathrm{C}$ for $5 \mathrm{~min}$ ) using HotStar Taq DNA polymerase (Qiagen, Crawley, UK). Primer sets were designed to amplify DNA fragments containing both methylated and unmethylated $\mathrm{CpG}$ dinucleotides. The primer sequences are: G1F (5'-TTA GGT GTG GGA TTT GYG TTT YGA TAG TT-3'); G1R (5'-CAA AAA AAA TAA TCT CTA ACR TCA ACR CAT TCT ACT A-3'); G1FN (5'-GGT TAT TGG TYG TTT GAG GAY GGT TAG TT-3'); G2F (5' ${ }^{\prime}$-TTA GGG TTT TTT TTT GGA GGG TTT AGT-3'); G2R (5'-AAA ACT AAT CCA TAA AAA CTA CTA ACA AAT- $\left.3^{\prime}\right)$; G2RN ( $5^{\prime}$-ACC TAA AAT CCA CAC TAC ACT AAA CCT ATA-3'); G3F ( $5^{\prime}$-AGA GGG AAT AGT TTT GAG ATT TTT YGG ATT TAT- $3^{\prime}$ ); G3R (5'-ATC CTC CAA ACA CCR CTA TCA CRC ATA TAA-3'); G3RN (5'-ATA ATC TCR AAA CRA AAA ACA AAA CCT ATA-3'); D1F (5'-TAT ATA GTG GGT ATT TTA ATT GTT TTT TAT- $\left.3^{\prime}\right)$; D1R ( $5^{\prime}$-TAA AAA AAC AAA CCC ATA AAC ATC CCC AAA-3'); D2F (5'-TTG GTA ATT AGT ATT TTT TAT TTT TA-3 $\left.{ }^{\prime}\right)$; D2R (5'-ACT TTT ATC ACA AAT AAC ATA CAT AAA C- $\left.3^{\prime}\right)$; D3F ( $5^{\prime}$-TTG TTT ATG TAT GTT ATT GTG GAT-3'); D3R (5'-TAA AAT CCC RAA CAC ACR TAC AAT AAT$3^{\prime}$ ); D3FN (5'-GTT AAG GTT TTG ATT GAG ATG TTG TGT G-3'); and D3RN (5'-TAT ACC CCT AAC CAT AAA AAC RCA AA-3'). Amplification products were purified from agarose gel using QiaQuick gel extraction kit (Qiagen, Crawley, UK), cloned into pGem T-Easy vector system (Promega, Southampton, UK). In all, eight to 10 individual clones for each DMR regions were sequenced using BigDye terminator cycle sequencing kit V 1.1/3.1 (PerkinElmer/Applied Biosystems, Warrington, UK) and run on an ABI377/3730.

\section{Methylation status of the intergenic germline-derived differentially methylated region (IG-DMR)}

A seminested PCR was performed to amplify the IG-DMR (nt position 51021-51180; GeneBank accession no. AL117190). The primer sequences are: IG-F (5' $5^{\prime}$ TTT TGA GGA GAT TGA TAT TTT TAG TTT TAT T- $\left.3^{\prime}\right)$; IG-R ( $5^{\prime}$-ATA AAC TAC ACT ACT AAA AAC TAC ATT TAA A-3'); and IG-Fnes (5'-TTA GGT TGG AAT TGT 
TAA GAG TTT GTG GAT T-3'). PCR was performed as previously described using HotStar Taq DNA polymerase (Qiagen) with an annealing temperature of $53^{\circ} \mathrm{C}$ and $1.5 \mathrm{mM} \mathrm{MgCl}_{2}$ for both firstround (primer set IG-F/IG-R) and second-round (primer set IGFnes/IG-R) PCRs. PCR products were then cloned and sequenced as described above.

\section{Expression analysis: reverse transcriptase (RT) and quantitative real-time PCR}

RNA (1 $\mu \mathrm{g})$ was reverse transcribed using Reverse Transcription Systems and oligo-dT primers (Promega) according to the manufacturer's protocols. cDNA $(1 \mu \mathrm{l})$ obtained was then used as template for RT-PCR amplification. A single-nucleotide polymorphism (SNP) previously identified in exon 5 of GTL2 and an SNP in exon 5 of DLK1 (Wylie et al, 2000) were used to analyse GTL2 and DLK1 gene expression. GTL2 and DLK1 cDNA were amplified using oligonucleotide primers described by Wylie et al (2000), except that for GTL2 reverse primer, GTL2RK (5'-TTC CAC GGA GTA GAG CGA GTC A-3'), was used. Amplification products were purified and sequenced as described above using primers: GTL2FS ( $5^{\prime}$-ATC CCT TTG GGA AAT TCT CAG G- $\left.3^{\prime}\right)$ and DLK1FS ( $5^{\prime}$-AGG CAC CTG CGT GGA TGA T-3'). For quantitative real-time PCR, total RNA from cell lines was extracted with the RNAzol B (Biogenesis, Poole, UK) according to the manufacturer's instruction and treated with DNAse 1 (Invitrogen, Paisley, UK). Total RNA $(1 \mu \mathrm{g})$ was reverse transcribed as described previously. The cDNA was used in triplicate in a real-time PCR analysis using a real-time Thermal Cycler Model 7900 (Applied Biosystems). The primer sets are: DLK1 (5'-GCG AGG ATG ACA ATG TTT GC- $3^{\prime}$ (forward) and 5'-AGC AGG CCC GAA CAT CTC TA-3' (reverse)) and GTL2 ( $5^{\prime}$-ATC AGC CAA GCT TCT TGG AA- $3^{\prime}$ (forward) and $5^{\prime}$-AGC TTC CAT CCG CAG TTC T-3' (reverse)). Beta-actin was used as a control for normalisation. PCR was performed in a $25 \mu \mathrm{l}$ volume that included $12.5 \mu \mathrm{l}$ of $2 \times$ Cyber green (Applied Biosystems), $25 \mathrm{ng}$ of cDNA template and $0.0125-0.025 \mathrm{pmol}$ of each primer. Relative RNA quantification was performed using the comparative $C_{\mathrm{T}}$ method. The fold differences in RNA expression are the mean value from three independent observations.

\section{Treatment of cell lines with 5-aza-2'-deoxycytidine (5-aza-dC)}

5-Aza-dC (Sigma, Gillingham, Dorset, UK) was freshly prepared in $\mathrm{ddH}_{2} \mathrm{O}$ at $2 \mathrm{mg} \mathrm{ml}^{-1}$ and filter sterilised. A total of $1 \times 10^{6}$ cells were plated in $75 \mathrm{~cm}^{2}$ flask in RPMI 1640 medium supplemented with $10 \%$ FCS and left to settle for $24 \mathrm{~h}$ (day 0 ). Cells were treated with $2 \mu \mathrm{M}$ of 5 -aza-dC at day 1 and 4 and harvested at day 5 . The culture medium was changed before each treatment and $24 \mathrm{~h}$ after treatment.

\section{RESULTS}

\section{Epigenetic analysis of $D L K 1 / G T L 2$ domain in neuroblastoma tumours and cell lines}

The methylation status of the GTL2 promoter DMR was assessed in four normal control blood DNA samples and all four cases demonstrated both methylated and unmethylated allele products. We then analysed tumour DNA from 20 primary neuroblastomas. We found that five of $20(25 \%)$ neuroblastoma tumours demonstrated only products from a methylated allele at the GTL2 promoter DMR. The other 15 tumours showed a normal result with methylated and unmethylated allele products. In four of five tumours with hypermethylation of the GTL2 promoter DMR, heterozygosity at a DLK1 SNP (c.564T $>$ C) $(n=-2)$ or at closely linked microsatellite markers (D14S598, D14S1426, D14S749 and D14S1006) excluded 14q32 maternal allele loss as a cause of the GTL2 promoter DMR hypermethylation.

In order to investigate whether GTL2 promoter DMR hypermethylation in tumours was associated with alterations in $D L K$ and GTL2 expression and imprinting, we examined the GTL2 promoter DMR methylation status in four neuroblastoma cell lines (SK-NF1, SK-N-AS, SK-N-DZ, Kelly). All four neuroblastoma cell lines demonstrated GTL2 promoter DMR hypermethylation (Figure 1A and B). One cell line, SK-N-AS, was heterozygous for a transcribed DLK1 SNP, thus enabling us to (a) exclude maternal allele loss as the cause of $5^{\prime}$ GTL2 DMR hypermethylation and (b) perform allele-specific expression studies to investigate DLK1 imprinting status. We also analysed DLK1 and GTL2 expression before and after treatment with the demethylating agent 5-azacytidine (5$\mathrm{AzaC}$ ) in the four neuroblastoma cell lines with GTL2 promoter DMR hypermethylation. In all cases, there was silencing of GTL2 expression in the untreated cell line and reactivation of GTL2 expression after treatment with 5-AzaC (Figure 1C and Table 1). In addition, 5 -AzaC treatment resulted in a reduction in DLK1 mRNA expression. Analysis of DLK1 allelic expression in the informative SK-N-AS neuroblastoma line demonstrated monoallelic (allele C) DLK1 expression pre- and post-treatment with 5-AzaC (Figure 2). Thus, hypermethylation of the GTL2 promoter DMR in the SK-N-AS
A
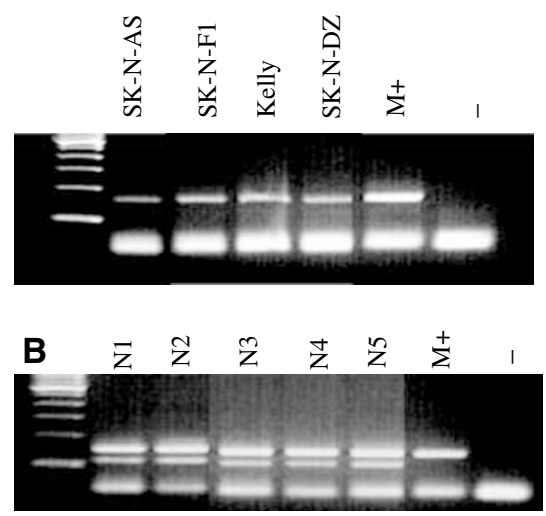

C

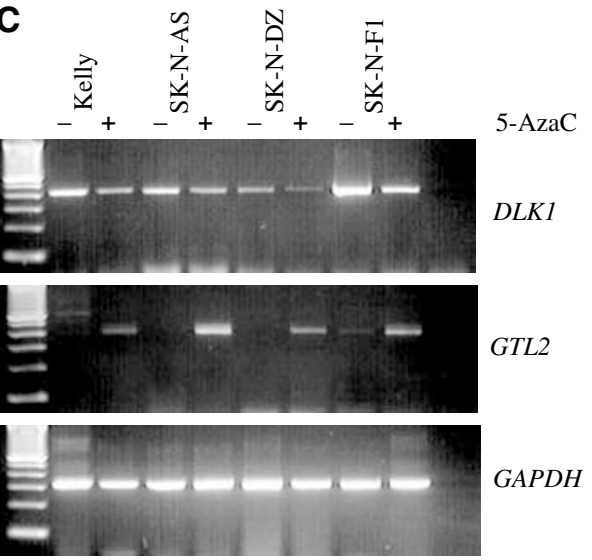

Figure I (A) Methylation-specific multiplexed PCR of the DMR upstream GTL2 promoter in neuroblastoma cell lines showing the presence of only methylated allele of $160 \mathrm{bp}$. M+ is in vitro methylated DNA. (B) Normal blood DNA was used as control showing both unmethylated (I20 bp) and methylated (I 60 bp) allele. (C) RT-PCR analysis of DLKI and GTL2 in four neuroblastoma cell lines before $(-)$ and after $(+)$ treatment with demethylating agent 5-AzaC. DLKI expression was reduced, while GTL2 expression was activated following 5-AzaC treatment. Molecular weight marker was a I00-bp ladder (Invitrogen). 
was associated with the upregulation of DLK1 expression and silencing of GTL2 expression, but not LOI of DLK1.

Hypermethylation of $5^{\prime}$ GTL2 promoter was observed in five of $20(25 \%)$ of neuroblastoma tumours. RNA was available from seven of the 20 tumours (see Figure 3). A low level of GTL2 expression was detected in the tumour with hypermethylation of the $5^{\prime}$ GTL2 promoter DMR (possibly caused by normal tissue contamination).

To establish the precise epigenetic status of individual CpGs within the GTL2 promoter DMR region, bisulphite sequencing was undertaken in four normal control blood DNA samples and in the SK-N-AS hypermethylated neuroblastoma cell line, which is heterozygous for DLK1 SNP. A total of $54 \mathrm{CpGs}$ were analysed in three subregions of the CpG-rich region upstream of GTL2 (G1 $n=12$ CpGs, G2 $n=19$ and G3 $n=21$ ). Between eight and 10 clones were sequenced from each of the normal blood samples and the methylation status of each of the $54 \mathrm{CpGs}$ determined (see Figure 4C). Comparison of the CpG methylation status of the GTL2 promoter DMR subregions in controls and the neuroblastoma cell line revealed that within subregions G1 and G2, there was extensive methylation of $\mathrm{CpGs}$ in SK-N-AS compared to normal control DNAs. However, in subregion G3, there was little difference between the $\mathrm{CpG}$ methylation status of normal control DNAs and the SK-N-AS cell line DNA.

Table I DLKI and GTL2 expression in neuroblastoma cell lines following 5-AzaC treatment analysed by real-time PCR

\begin{tabular}{lcc}
\hline Cell line & $\begin{array}{c}\text { DLKI } \\
\text { Fold change }( \pm \text { s.d. })^{\mathbf{a}} \\
\text { after 5-AzaC } \\
\text { treatment }\end{array}$ & $\begin{array}{c}\text { GTL2 } \\
\text { Fold change }( \pm \text { s.d. })^{\mathbf{a}} \\
\text { after 5-AzaC } \\
\text { treatment }\end{array}$ \\
\hline SK-N-DZ & $0.282 \pm 0.056$ & $5.437 \pm 2.037$ \\
SK-N-AS & $0.219 \pm 0.097$ & $3.953 \pm 0.724$ \\
SK-N-FI & $0.365 \pm 0.259$ & $2.773 \pm 0.570$ \\
Kelly & $0.173 \pm 0.015$ & $2.693 \pm 0.825$ \\
\hline
\end{tabular}

5-AzaC = 5-azacytidine; PCR = polymerase chain reaction; s.d. = standard deviation. ${ }^{a}$ The fold differences in RNA expression are the mean \pm s.d. of three independent observations.

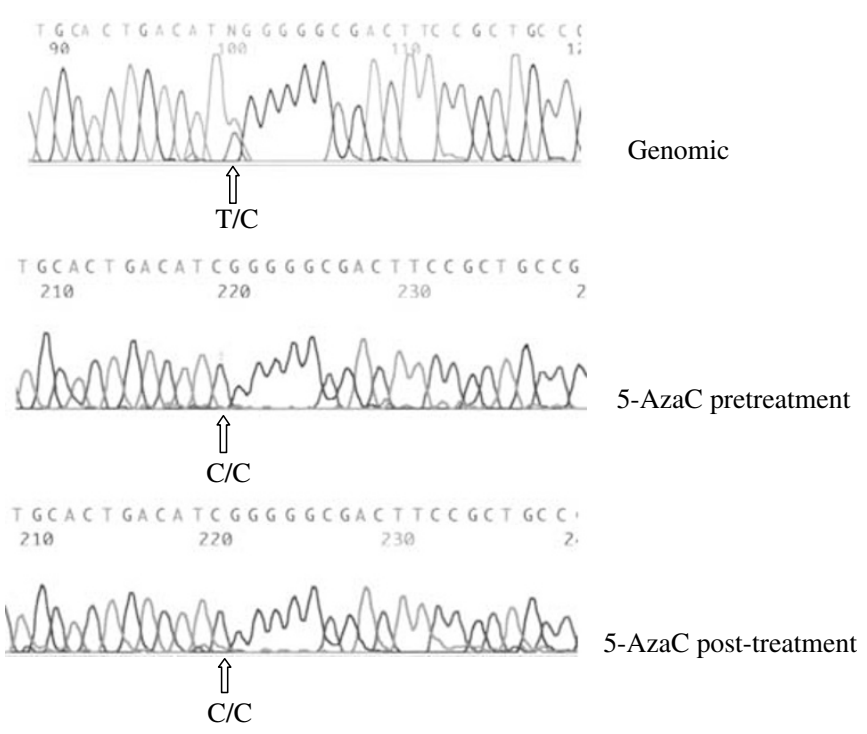

Figure 2 Analysis of DLKI allele expression in the informative SK-N-AS cell line. DLKI is monoallelically expressed before and following treatment with 5-AzaC.

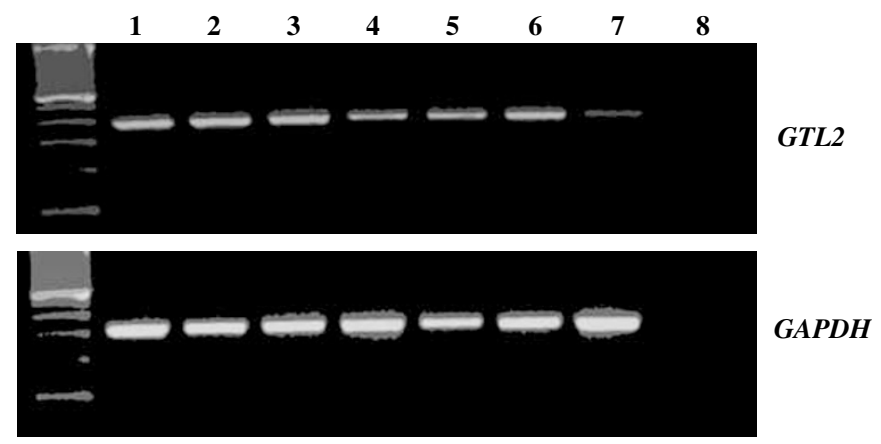

Figure 3 RT-PCR showing GTL2 expression in neuroblastoma tumours without gain of methylation at 5' GTL2 DMRs (lanes I -6) and tumour with gain of methylation at 5' GTL2 DMRs (lane 7). Low level of GTL2 expression in this tumour may be caused by normal tissue contamination. Lane 8 is a negative control and GAPDH was used as unlinked control gene.

\section{Methylation analysis of the GTL2 promoter DMR in phaeochromocytoma and Wilms' tumour}

Methylation analysis of the GTL2 DMR was then undertaken in 20 phaeochromocytomas and 40 Wilms' tumours. GTL2 promoter DMR hypermethylation was detected in two phaeochromocytomas $(10 \%)$ and one Wilms' tumour (2.5\%). Genotyping with $14 \mathrm{q} 32$ microsatellite markers (D14S598, D14S1426, D14S1006, D14S749) excluded 14q32 allele loss in all three tumours.

\section{Methylation analysis of IG-DMR}

Recently, an IG-DMR was demonstrated to function as an imprinting control element for all imprinted genes on the maternal chromosome only (Lin et al, 2003). To determine whether GTL2 promoter DMR hypermethylation was associated with epigenetic alterations at the upstream IG-DMR, we analysed the methylation status of the eight CpGs within the IG-DMR in four normal control DNAs and in four neuroblastoma cell lines with $5^{\prime}$ GTL2 DMR methylation. Eight to 12 individual clones for each were analysed for IG-DMR CpGs methylation status. In the four normal control samples, $32 \%$ of IG-DMR CpGs sequenced were methylated, while in the SK-N-AS neuroblastoma cell line with GTL2 promoter DMR hypermethylation, all eight CpGs ( $n=12$ clones) were methylated. In addition, the three neuroblastoma cell lines with $5^{\prime}$ GTL2 DMR hypermethylation (but uninformative for $D L K 1$ imprinting status) showed almost complete methylation at all IG-DMR CpGs analysed (see Figure 4B). Similarly, analysis of the IG-DMR CpG methylation status in four primary tumours (two neuroblastoma, one phaeochromocytoma and one Wilms' tumour) with GTL2 promoter DMR hypermethylation demonstrated heavy CpG methylation (although less complete than in the neuroblastoma cell lines, possibly because of normal tissue contamination). In contrast, cell lines and tumours with GTL2 promoter DMR and IGDMR hypermethylation did not show any differences from normal controls at the CpG-rich region upstream of the DLK1 promoter nor at the two CpG-rich regions downstream of the DLK1 promoter.

\section{DISCUSSION}

We detected epigenetic changes within the GTL2 promoter DMR (and the IG-DMR) in 25\% of neuroblastoma tumours, $10 \%$ of phaeochromocytoma and $2.5 \%$ of Wilms' tumours analysed. In most cases, allele loss was excluded as a cause of the apparent hypermethylation. All cases with GTL2 promoter DMR methylation also demonstrated hypermethylation at the upstream IG-DMR region, but epigenetic alterations were not detected in the three 


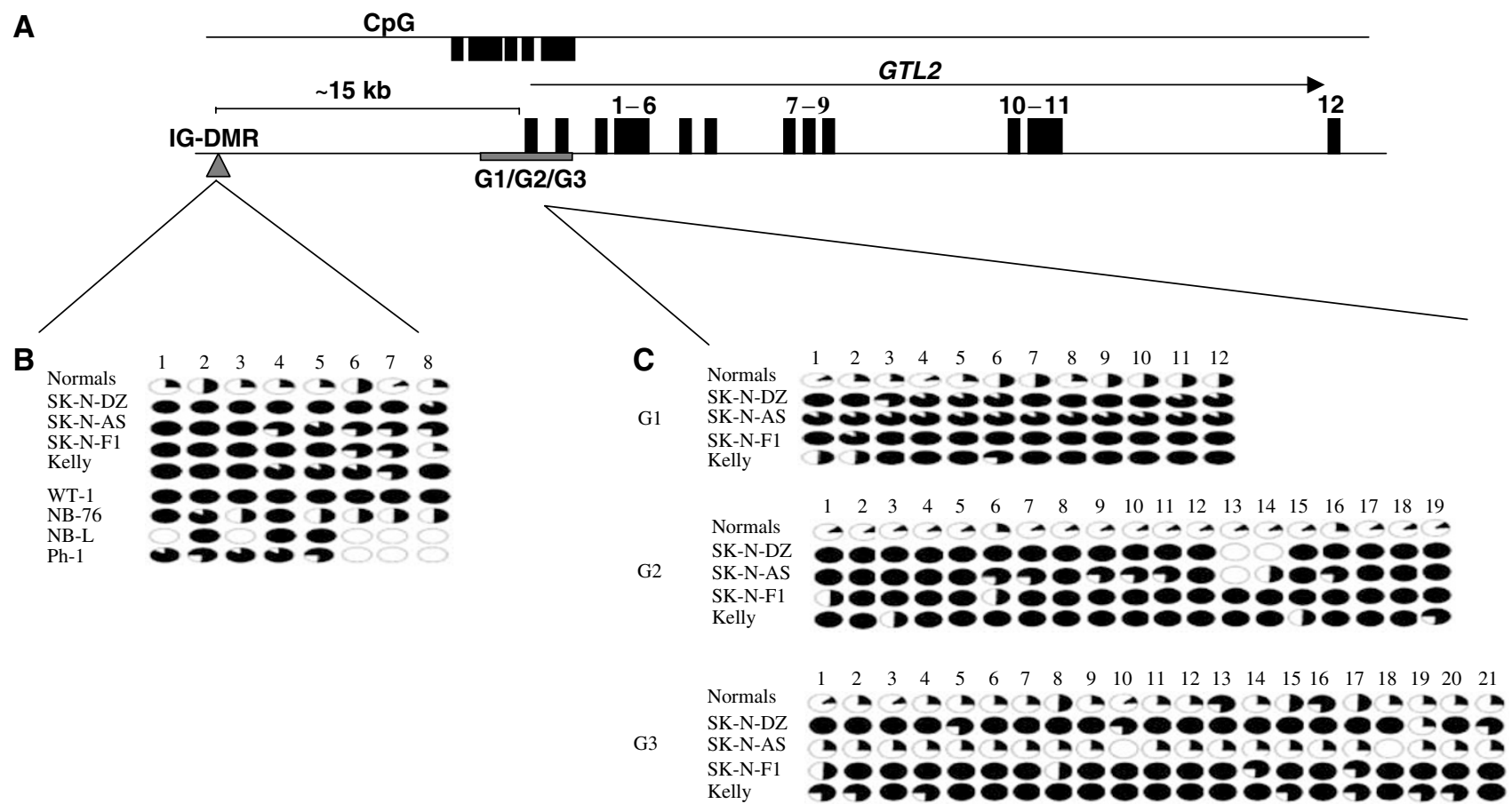

Figure 4 (A) Schematic representation of GTL2 and IG-DMRs in human showing the position of regions analysed: GI =-363 bp $\rightarrow-|6|$ bp upstream $\mathrm{G} 2=+293 \mathrm{bp} \rightarrow+673 \mathrm{bp}$ downstream, and $\mathrm{G} 3=+1213 \mathrm{bp} \rightarrow+1583 \mathrm{bp}$ downstream of GTL2 transcription start site, GeneBank accession no. AY3I4975; IG-DMR = nt 5I02I-5II80, GeneBank accession no. AL II7I90). (B) Methylation status of the CpGs in the IG-DMR in the normal blood, neuroblastoma cell lines, a Wilms' tumour, two neuroblastoma tumours and a phaeochromocytoma tumour with gain of methylation at the $5^{\prime}$ GTL2 DMRs. (C) Methylation status of GTL2 DMRs in neuroblastoma cell lines. The methylation status is shown in circles. Open and filled circles indicates complete unmethylation and full methylation, respectively. Partially filled circles indicate the degree of partial methylation.

CpG-rich regions close to DLK1. Analysis of DLK1 and GTL2 expression in four neuroblastoma cell lines with GTL2 DMR hypermethylation demonstrated repression of GTL2 transcription and re-expression of GTL2 after treatment with 5-AzaC. In most cell lines, re-expression of GTL2 after treatment with 5-AzaC was associated with downregulation of DLK1 expression. Furthermore, in an informative neuroblastoma cell line (SK-N-AS), there was no evidence of LOI of DLK1. The absence of LOI of DLK1 is consistent with other reports of monoallelic DLK1 expression in neuroblastoma, brain tumours and lymphoma (van Limpt et al, 2003; Yin et al, 2004). The DLK1/GTL2 imprinted domain has similarities to the IGF2/H19 gene at 11 p15.5. In both cases, two closely linked genes are reciprocally imprinted, and both $H 19$ and GTL2 do not appear to encode a protein. Like $H 19$ and Igf2, Gtl2 and Dlk transcripts can be found in the same tissues during development (Takada et al, 2000). In Beckwith-Wiedemann syndrome and sporadic Wilms' tumour, hypermethylation of the H19 promoter DMR (and the upstream 'CTCF box' DMR) is associated with silencing of $H 19$ expression (Cui et al, 2001; Nakagawa et al, 2001). We identified hypermethylation of the GTL2 DMRs in tumours and cell lines, so there are apparent similarities between epigenetics at the H19 and GTL2 loci in human neoplasia, although the frequency of GTL2 hypermethylation in Wilms' tumour is much less than that at H19. However, whereas de novo hypermethylation of the H19 promoter and CTCF box DMRs is associated with $H 19$ silencing and LOI of IGF2, LOI of DLK1 was not associated with GTL2 promoter DMR and IG-DMR hypermethylation. In mice, deletion of the unmethylated copy of the IG-DMR leads to bidirectional LOI of all genes in the imprinted cluster after maternal inheritance, but imprinting is unaltered after paternal transmission of the deleted methylated copy (Lin et al, 2003). This asymmetric regulation of imprinting distinguishes the imprinting control mechanisms in the $11 \mathrm{p} 15.5$ and the $14 \mathrm{q} 32$ imprinted gene clusters. The Callipyge phenotype demonstrates complex inheritance patterns. Thus, while paternal inheritance of the Callipyge mutation is associated with muscle hypertrophy, and maternal transmission is not, surprisingly, homozygotes do not demonstrate the phenotype. This unusual inheritance pattern (known as polar overdominance) has been attributed to the Callipyge mutation affecting a long-range control element resulting in enhanced expression in cis of all genes in the heterozygote sheep (but with no change in their imprinting) (Charlier et al, 2001; Freking et al, 2002; Georges et al, 2003). Furthermore, the absence of a mutant phenotype in the homozygotes suggests that overexpression of imprinted genes on the maternal chromosome abrogates the functional defect caused by the paternal chromosome in trans. Hence, when the Callipyge mutation is paternally inherited, DLK1 transcription is upregulated, while GTL2 is upregulated after maternal transmission (Charlier et al, 2001; Freking et al, 2002; Georges et al, 2003). In homozygotes, it is postulated that GTL2-associated transcripts negatively regulate DLK1 transcripts; however, the precise mechanism is not known. Our finding that hypermethylation of the GTL2 promoter and upstream DMR is associated with silencing of GTL2 and upregulation of DLK1 without LOI would be consistent with a model, whereby GTL2-associated transcripts negatively regulate DLK1 transcription and further analysis of neuroblastoma cell lines with GTL2 hypermethylation and silencing may provide important insights into the mechanisms of imprinting control in the $14 \mathrm{q} 32$ imprinted domain.

DLK1 encodes a transmembrane protein with six EGF-like repeats that shows homology to the Delta gene in Drosophila melanogaster, which is involved in the Notch signalling pathway. The precise function of the DLK1 protein is unclear, but DLK1 expression is upregulated in myelodysplastic syndrome, a slowly progressing haematological malignancy, and in uterine leiomyomata 
(compared to normal myometrium) (Miyazato et al, 2001; Tsibris et al, 2002). In addition, overexpression of the DLK1 protein is reported to prevent adipocyte differentiation of 3T3-L1 cells in response to IGF1 or insulin. These latter effects were attributed to changes in the activation levels and kinetics of extracellularregulated kinase/mitogen-activated protein kinase (Ruiz-Hidalgo et al, 2002). However, although it might be postulated that increased DLK1 expression might be pro-oncogenic, there is no direct evidence for this. Indeed, van Limpt et al (2003) suggested that neuroblastomas DLK1 expression increases during chromaffin cell lineage differentiation and high DLK1 expression in neuroblastoma cell lines may merely indicate that the neuroblastoma has developed from a later stage chromaffin cell precursor. Hence, upregulation of DLK1 expression associated with GTL2 promoter and intergenic DMR hypermethylation may be coincidental to tumorigenesis. GTL2 promoter and intergenic DMR hypermethylation was associated with transcriptional silencing of GTL2 and treatment with 5-AzaC resulted in re-expression of GTL2. Recently, an isoform of GTL2, MEG3a, was reported to be expressed highly in normal pituitary and brain and in other tissues including

\section{REFERENCES}

Charlier C, Segers K, Karim L, Shay T, Gyapay G, Cockett N, Georges M (2001) The Callipyge mutation enhances the expression of coregulated imprinted genes in cis without affecting their imprinting status. Nat Genet 27: $367-369$

Cui H, Niemitz EL, Ravenel JD, Onyango P, Brandenburg SA, Lobanenkov VV, Feinberg AP (2001) Loss of imprinting of insulin-like growth factorII in Wilms' tumor commonly involves altered methylation but not mutations of CTCF or its binding site. Cancer Res 61: $4947-4950$

Eggermann T, Mergenthaler S, Eggermann K, Albers A, Linnemann K, Fusch C, Ranke MB, Wollmann HA (2001) Identification of interstitial maternal uniparental disomy (UPD) (14) and complete maternal $\mathrm{UPD}(20)$ in a cohort of growth retarded patients. J Med Genet 38: 86-89

Feinberg AP, Cui H, Ohlsson R (2002) DNA methylation and genomic imprinting: insights from cancer into epigenetic mechanisms. Semin Cancer Biol 12: $389-398$

Freking BA, Murphy SK, Wylie AA, Rhodes SJ, Keele JW, Leymaster KA, Jirtle RL, Smith TP (2002) Identification of the single base change causing the Callipyge muscle hypertrophy phenotype, the only known example of polar overdominance in mammals. Genome Res 12: 14961506

Georges M, Charlier C, Cockett N (2003) The Callipyge locus: evidence for the trans interaction of reciprocally imprinted genes. Trends Genet 19: $248-252$

Georgiades P, Watkins M, Surani MA, Ferguson-Smith AC 2000 Parental origin-specific developmental defects in mice with uniparental disomy for chromosome 12. Development 127: 4719-4728

Hao Y, Crenshaw T, Moulton T, Newcomb E, Tycko B (1993) Tumoursuppressor activity of H19 RNA. Nature 365: 764-767

Herman JG, Graff JR, Myohanen S, Nelkin BD, Baylin SB (1996) Methylation-specific PCR: a novel PCR assay for methylation status of CpG islands. Proc Natl Acad Sci USA 93: 9821 - 9826

Kobayashi S, Wagatsuma H, Ono R, Ichikawa H, Yamazaki M, Tashiro H, Aisaka K, Miyoshi N, Kohda T, Ogura A, Ohki M, Kaneko-Ishino T, Ishino F (2000) Mouse Peg9/Dlk1 and human PEG9/DLK1 are paternally expressed imprinted genes closely located to the maternally expressed imprinted genes: mouse Meg3/Gtl2 and human MEG3. Genes Cells 5: $1029-1037$

Kurosawa K, Sasaki H, Sato Y, Yamanaka M, Shimizu M, Ito Y, Okuyama T, Matsuo M, Imaizumi K, Kuroki Y et al (2002) Paternal UPD14 is responsible for a distinctive malformation complex. Am J Med Genet 110: $268-272$

Lin SP, Youngson N, Takada S, Seitz H, Reik W, Paulsen M, Cavaille J, Ferguson-Smith AC (2003) Asymmetric regulation of imprinting on the maternal and paternal chromosomes at the Dlk1-Gtl2 imprinted cluster on mouse chromosome 12. Nat Genet 35: 97-102

Maher ER, Reik W (2000) Beckwith-Wiedemann syndrome: imprinting in clusters revisited. J Clin Invest 105: 247-252 adrenal (Zhang et al, 2003), but not in many pituitary tumours. Furthermore, transfection of MEG3a into a HeLa cell line inhibited cell proliferation in the in vitro colony formation and growth rate assays. Hence, although neither GTL2 nor MEG3a have been shown to encode an expressed protein, GTL2 promoter and intergenic DMR hypermethylation might promote tumorigenesis by downregulating GTL2 expression. These findings are similar to those reported for H19 (Hao et al, 1993), although the precise role of H19 silencing per se in Wilms' tumour and tumour susceptibility in Beckwith - Wiedemann syndrome has not been unequivocally established (Tycko, 2000). Thus, further investigations of the potential roles of GTL2, MEG3a and epigenetic changes in the $D L K 1 / G T L 2$ domain are indicated.

\section{ACKNOWLEDGEMENTS}

We thank AICR British Heart Foundation and Cancer Research UK for financial support.
Miyazato A, Ueno S, Ohmine K, Ueda M, Yoshida K, Yamashita Y, Kaneko T, Mori M, Kirito K, Toshima M, Nakamura Y, Saito K, Kano Y, Furusawa S, Ozawa K, Mano H (2001) Identification of myelodysplastic syndrome-specific genes by DNA microarray analysis with purified hematopoietic stem cell fraction. Blood 98: 422-427

Miyoshi N, Wagatsuma H, Wakana S, Shiroishi T, Nomura M, Aisaka K, Kohda T, Surani MA, Kaneko-Ishino T, Ishino F (2000) Identification of an imprinted gene, Meg3/Gtl2 and its human homologue MEG3, first mapped on mouse distal chromosome 12 and human chromosome $14 \mathrm{q}$. Genes Cells 5: $211-220$

Murphy SK, Wylie AA, Coveler KJ, Cotter PD, Papenhausen PR, Sutton PR, Shaffer LG, Jirtle RL (2003) Epigenetic detection of human chromosome 14 uniparental disomy. Hum Mutat 22: $92-97$

Nakagawa H, Chadwick RB, Peltomaki P, Plass C, Nakamura Y, de La Chapelle A (2001) Loss of imprinting of the insulin-like growth factor II gene occurs by biallelic methylation in a core region of $\mathrm{H} 19$-associated CTCF-binding sites in colorectal cancer. Proc Natl Acad Sci USA 98: $591-596$

Paulsen M, Takada S, Youngson NA, Benchaib M, Charlier C, Seger K, Georges M, Ferguson-Smith AC (2001) Comparative sequence analysis of the imprinted Dlk1-Gtl2 locus in three mammalian species reveals highly conserved genomic elements and refines comparison with the Igf2-H19 region. Genome Res 11: $2085-2094$

Reik W, Walter J (2001) Genomic imprinting: parental influence on the genome. Nat Rev Genet 2: $21-32$

Ruiz-Hidalgo MJ, Gubina E, Tull L, Baladron V, Laborda J (2002) DLK modulates mitogen-activated protein kinase signaling to allow or prevent differentiation. Exp Cell Res 274: 178-188

Schmidt JV, Matteson PG, Jones BK, Guan XJ, Tilghman SM (2000) The Dlk1 and Gtl2 genes are linked and reciprocally imprinted. Genes Dev 14: $1997-2002$

Takada S, Paulsen M, Tevendale M, Tsai CE, Kelsey G, Cattanach BM, Ferguson-Smith AC (2002) Epigenetic analysis of the Dlk1-Gtl2 imprinted domain on mouse chromosome 12: implications for imprinting control from comparison with Igf2-H19. Hum Mol Genet 11: $77-86$

Takada S, Tevendale M, Baker J, Georgiades P, Campbell E, Freeman T, Johnson MH, Paulsen M, Ferguson-Smith AC (2000) Delta-like and gtl2 are reciprocally expressed, differentially methylated linked imprinted genes on mouse chromosome 12. Curr Biol 10: 1135-1138

Tsibris JC, Segars J, Coppola D, Mane S, Wilbanks GD, O’Brien WF, Spellacy WN (2002) Insights from gene arrays on the development and growth regulation of uterine leiomyomata. Fertil Steril 78: 114-121

Tycko B (2000) Epigenetic gene silencing in cancer. J Clin Invest 105: $401-407$

van Limpt V, Chan A, Caron H, Sluis PV, Boon K, Hermus MC, Versteeg R (2000) SAGE analysis of neuroblastoma reveals a high expression of the 
Epigenetic alteration at the DLKI-GTL2 imprinted domain

D Astuti et al

human homologue of the Drosophila Delta gene. Med Pediatr Oncol 35: $554-558$

van Limpt VAE, Chan AJ, van Sluis PG, Caron HN, van Noesel CJM, Versteeg R (2003) High delta-like expression in a subset of neuroblastoma cell lines corresponds to a differentiated chromaffin cell type. Int $J$ Cancer 105: 61-69

Weksberg R, Smith AC, Squire J, Sadowski P (2003) Beckwith - Wiedemann syndrome demonstrates a role for epigenetic control of normal development. Hum Mol Genet 12: R61 - R68
Wylie AA, Murphy SK, Orton TC, Jirtle RL (2000) Novel imprinted DLK1/ GTL2 domain on human chromosome 14 contains motifs that mimic those implicated in IGF2/H19 regulation. Genome Res 10: 1711-1718

Yin D, Xie D, De Vos S, Liu G, Miller CW, Black KL, Koeffler HP (2004) Imprinting status of DLK1 gene in brain tumors and lymphomas. Int $J$ Oncol 24: $1011-1015$

Zhang X, Zhou Y, Mehta KR, Danila DC, Scolavino S, Johnson SR, Klibanski A (2003) A pituitary-derived MEG3 isoform functions as a growth suppressor in tumor cells. J Clin Endocrinol Metab 88: 5119-51126 